\title{
Ti6Al4V Nanotubes Filled with Silver Nanoparticles as a Possible Antibacterial Surface for Implants
}

\author{
Eva Průchová ${ }^{1}$, Michaela Kosová ${ }^{2}$, Petra Jarolímová ${ }^{1}$, Luděk Joska ${ }^{1}$, Vojtěch Hybášek ${ }^{1}$ \\ ${ }^{1}$ University of Chemistry and Technology, Prague, Department of Metals and Corrosion Engineering, Technická 5, Praha \\ 6, Czech Republic. E-mail: pruchovv@vscht.cz, Petra.Jarolimova@vscht.cz, Ludek.Joska@vscht.cz \\ ${ }^{2}$ University of Chemistry and Technology, Prague, Department of Dairy, Fat and Cosmetic Science, Technická 5, Praha 6, \\ Czech Republic. E-mail: kosovam@vscht.cz
}

\begin{abstract}
The presented work was focused on the use of Ti6Al4V alloy with nanostructured surface and deposited silver nanoparticles as a material with antibacterial surface. Thanks to the electrochemically formed nanotubular oxide structure, a large area was available for silver deposition. Silver was photo-reduced from the silver nitrate solution. The ultrasonic treatment allowed the penetration of a silver source electrolyte into the whole depth of the tubes. Transmission electron microscopy images confirmed the presence of silver nanoparticles with size from units of nanometers up to $15 \mathrm{~nm}$. Nanosilver was present throughout the length of the nanotubes. Samples with photoreduced silver will be able to provide antibacterial activity not only in critical hours after implantation but also in the longer term due to the subsequent release of silver from the volume of nanotubes. The prolonged antibacterial effect has been demonstrated against Staphylococcus aureus.
\end{abstract}

Keywords: Titanium, Nanostructure, Nanosilver, Antibacterial, Photo-reduction

\section{Introduction}

Titanium and its alloys are widely used materials in orthopedics and dentistry. In 1954, well known Ti6Al4V alloy was introduced and during following years, it has become the first choice material $[1,2]$. To enhance the bioactivity of its surface, electrochemical oxidation can be used. One of the possibilities is anodic oxidation. Many studies have been focused on developing and optimizing the formation of self-organized nanotubes onto titanium containing alloys [3-6]. This structure can be used as a substrate for anchoring antimicrobial agents [7]. Foreign material implanted in the patient body is a preferential area for bacterial adhesion. Consequently, bacterial contamination may be a serious problem that may result in implant failure [8-10]. Therefore, it seems effective to anchor antibacterial agents directly onto the surface of the biomaterial [11]. One of the possible bactericides could be silver which inhibits broad range of microorganisms. But the bacterial resistance against it is rarely reported $[12,13]$. Many possible procedures of silver or other antibacterial agents deposition are known from the literature. In Bosseti's research, silver was anchored using IBAD technique (Ion Beam Assisted Deposition). This technique allowed the creation of gradual transition between the substrate material and the deposited silver film. The depth of silver penetration into the substrate surface reached $150 \mathrm{~nm}$ [14]. Another possibility is the use of PVD (Physical Vapour Deposition) technique [15]. Alternatively, the application of layers to the substrate by the solgel method was also applied [16]. The most of methods mentioned above allow the anchoring of silver only on the surface of the material. For the deeper penetration of silver and possible longer-term antimicrobial effect, titanium was anodized in the electrolyte with the broad scale of $\mathrm{AgNO}_{3}$ concentrations. The results showed that highly ordered nanopores on titanium surface can be easily fabricated. Silver nanoparticles were embedded in $\mathrm{TiO}_{2}$ substrates [17].
$\mathrm{TiO}_{2}$ layer on the titanium based alloys is also promising due to its semiconductive photo-reductive properties $[18,19]$. After the exposure to UV light, the material had also excellent antimicrobial properties [7].

In the Esfandiari research, created nanostructures on titanium foils were immersed in various concentrations of $\mathrm{AgNO}_{3}$ solution for 15 minutes and consequently irradiated by UV for next 15 minutes. Photocatalysis caused by UV irradiation resulted in the reduction of $\mathrm{Ag}^{+}$to $\mathrm{Ag}^{0}$. Silver particles were analyzed and their size varied from 12 to $40 \mathrm{~nm}$. The amount of deposited silver nanoparticles and their sizes decreased with decreasing the silver nitrate concentrations. Massive deposition processed at $1.5 \mathrm{M}$ $\mathrm{AgNO}_{3}$ resulted in formation of large agglomerates and a thin layer of nanoparticles densely covered the nanotube arrays [20].

The aim of this work was to prepare an antibacterial surface with prolongated efficiency. It could be achieved by filling the nanotubes with silver in the whole volume. There must be also developed a proper method of sample preparation for TEM which can verify that nanotubes are filled, and which enabled to evaluate the amount of silver nanoparticles by EDS. Finally, the antibacterial activity will be determinate in different time periods after the exposure in physiological solution.

\section{Experiment}

Discs like samples $\varnothing 15 \mathrm{~mm}$ of Ti6Al4V ELI (TiAlV) were ground up to P2500 emery paper. These samples were cleaned in the ultrasonic bath in demineralized (demi) water, ethanol and acetone. Anodic oxidation was managed by Jaissle Potentiostat-Galvanostat IMP 88 PC$200 \mathrm{~V}$ with the control unit PGU-AUTO Extern. Nanostructures (NS) creation was carried out in $1 \mathrm{~mol} / \mathrm{l}$ $\left(\mathrm{NH}_{4}\right)_{2} \mathrm{SO}_{4}$ containing 0.2 wt. $\% \mathrm{NH}_{4} \mathrm{~F}$ electrolyte. The procedure consisted of a potential sweep of $100 \mathrm{mV} / \mathrm{s}$ to a potential $20 \mathrm{~V}$ against silver/silver chloride electrode (3 $\mathrm{mol} / \mathrm{l} \mathrm{KCl}$ ) followed by a $2200 \mathrm{~s}$ delay at this potential. 
Samples were cleaned again after the procedure (sonication in demi-water, ethanol and acetone).

To fill the TiAlV NS with silver, the samples were sonicated in a $0.1 \mathrm{~mol} / \mathrm{IgNO}_{3}$ solution for 20 minutes. Next step was UV irradiation, which was carried out by a Philips $50 \mathrm{~W}$ germicide lamp, $\lambda=253 \mathrm{~nm}, 10$ minutes, with the $15 \mathrm{~cm}$ distance from the sample. The samples were then rinsed gently with demi-water and ethanol.

The surface morphology of NS samples was characterized by scanning electron microscope (SEM) TESCAN VEGA 3 LMU with EDS analyzer Oxford Instruments Xmax. The diameter of nanotubes was measured based on image analysis using ImageJ programme. Final EDS results were the average of the values found from 3 different sites on each sample, from the area $2 \mathrm{~mm}^{2}$. Images of a single nanotube were taken on transmission electron microscopy (TEM) EFTEM Jeol 2200 FS with EDS analyzer Oxford Instruments, using the same static approach from the area $160 \mu \mathrm{m}^{2}$.

The antimicrobial tests were carried out with as-prepared surfaces and with pre-exposed samples. Samples after nanostructuring and silver photo-reduction (NSAg0h) were exposed for 12, 24 and 48 hours in a cuvette with $20 \mathrm{ml}$ of physiological saline solution $(9 \mathrm{~g} / 1$ $\mathrm{NaCl}, 37^{\circ} \mathrm{C}$ ). After the exposure, samples were cleaned in the demi-water in the ultrasonic bath for 3 minutes. Thus, three types of samples NSAg12h, NSAg24h, NSAg48h were prepared. This set of samples was prepared to estimate the time dependency of antibacterial effect. The ground sample (P2500) of TiAlV alloy was used as negative control, where no inhibition was expected and all modifications were compared with this sample. Pure silver (Ag 4N) was used as positive control and the maximum inhibition was expected. Determination of antibacterial activity was repeated four times for each tested sample. New samples were used for each measurement.

Indicator strains of Staphylococcus aureus ATCC 6538 were cultivated in Brain Heart Infusion (BHI) broth (HiMedia, India) adjusted to $\mathrm{pH}$ 7.0. Cultivation medium was inoculated with $1 \%(\mathrm{v} / \mathrm{v})$ inoculum and cultivated aerobically at $37^{\circ} \mathrm{C}$ for $18 \mathrm{~h}$. A fresh culture of $S$. aureus was diluted with a physiological solution to initial concentration $10^{5} \mathrm{CFU} / \mathrm{ml}$. Subsequently, $100 \mu \mathrm{l}$ of suspension was dosed on the surface of tested samples and cultivated for $5 \mathrm{~h}$ at $20^{\circ} \mathrm{C}$, aerobically. After the cultivation, samples with bacterial suspension were washed in the exactly defined amount of physiological solution and diluted tenfold. Appropriate dilution of $0.1 \mathrm{ml}$ suspension was spread on the surface of Baird-Parker agar. Petri dishes were cultivated at $37{ }^{\circ} \mathrm{C}$ for $48 \mathrm{~h}$, aerobically. The number of microorganisms present in the sample was determined as a weighted average of consecutive dilutions (CSN EN ISO 7218, 2008). Antimicrobial efficiency was evaluated as a ratio of the number of microorganisms in the control sample $\left(\mathrm{N}_{\mathrm{c}}\right)$ (negative control) minus the number of microorganisms in the tested sample $\left(\mathrm{N}_{\mathrm{A}}\right)$ divided by $\mathrm{N}_{\mathrm{c}}$.

\section{Results and discussion}

The electrochemical oxidation under the conditions mentioned above resulted in the creation of nanotubes. TiAlV alloy microstructure consists of two phases, $\alpha$ and $\beta$. Beta areas contain a higher amount of vanadium which is less corrosion resistant to a fluoride-containing electrolyte. Therefore, many cavities after $\beta$ phases occurred on the nanostructured surface. The inner diameter of nanotubes ranged from 16 to $48 \mathrm{~nm}$ (Fig. 2), the size between $28-36 \mathrm{~nm}$ was the most frequent. The length of the nanotubes was up to $1 \mu \mathrm{m}$.

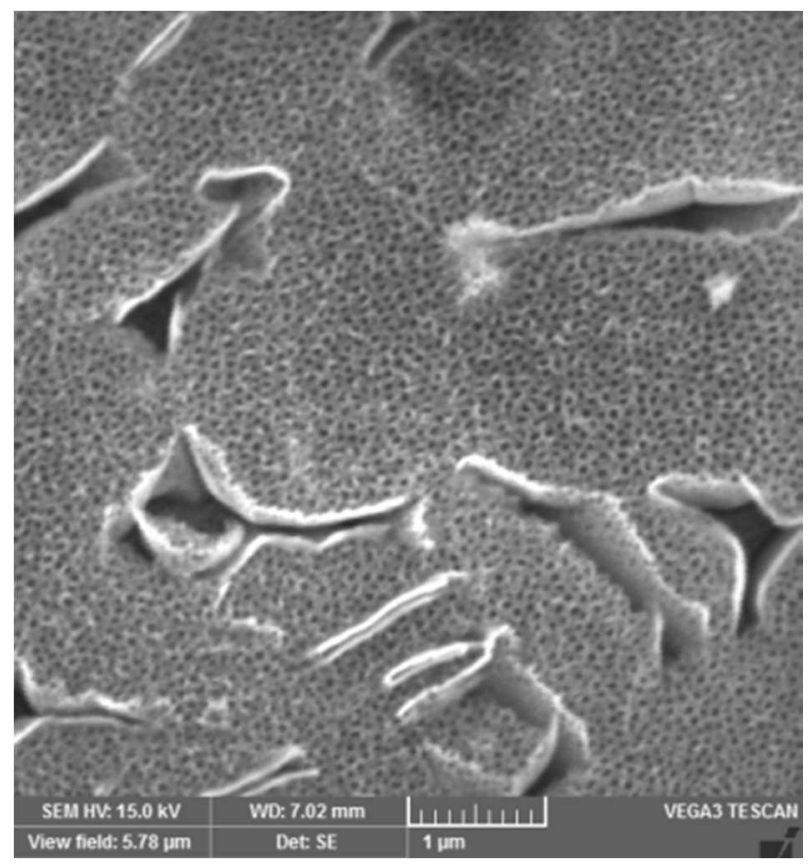

Fig. 1 Nanostructed TiAlV surface

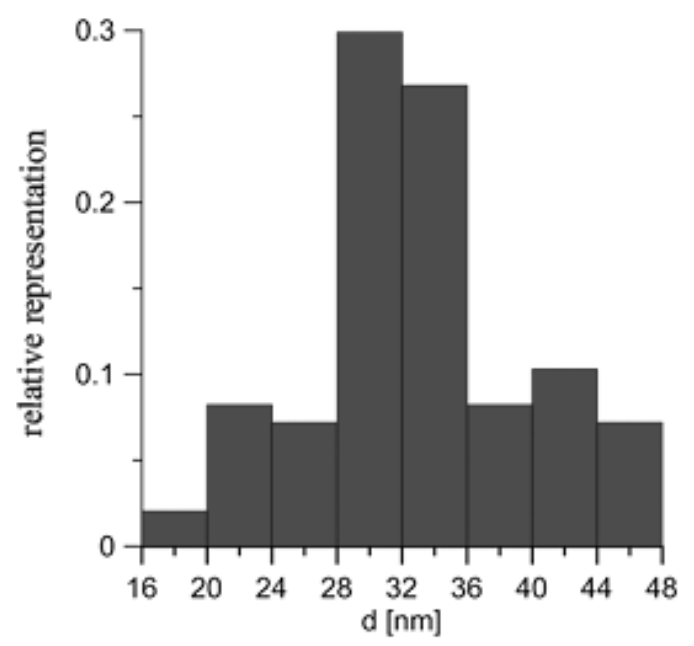

Fig. 2 Histogram of nanotube diameters

The ultrasonic treatment of samples in $\mathrm{AgNO}_{3}$ solution resulted in filling the whole volume of the nanostructure by the silver source. UV irradiation allowed the photochemical reduction of silver nitrate and the creation of silver nanoparticles. Acquired SEM images (Fig. 3) did not show significant changes in comparison with the morphology of the nanostructured surface (Fig. 1). However, the EDS analyses detected the silver presence in concentration $1.15 \pm 0.25 \mathrm{wt}$ \% $\%$, which confirms that silver was present in and on the surface, probably in the form of 
nanoparticle.

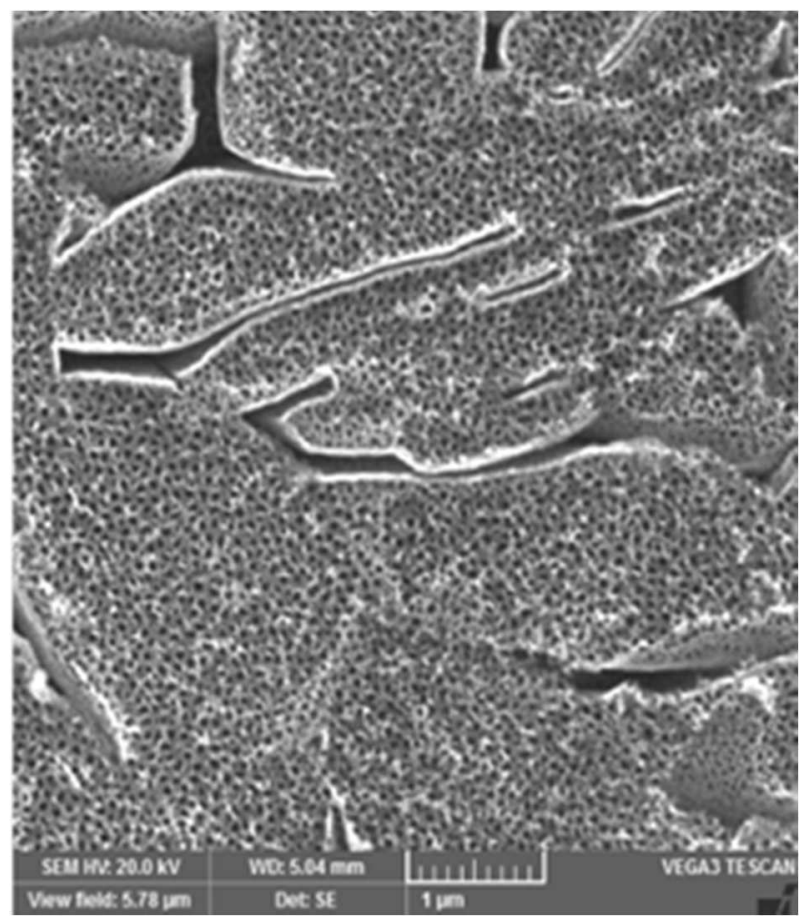

Fig. 3 Nanostructured surface after photo-reduction

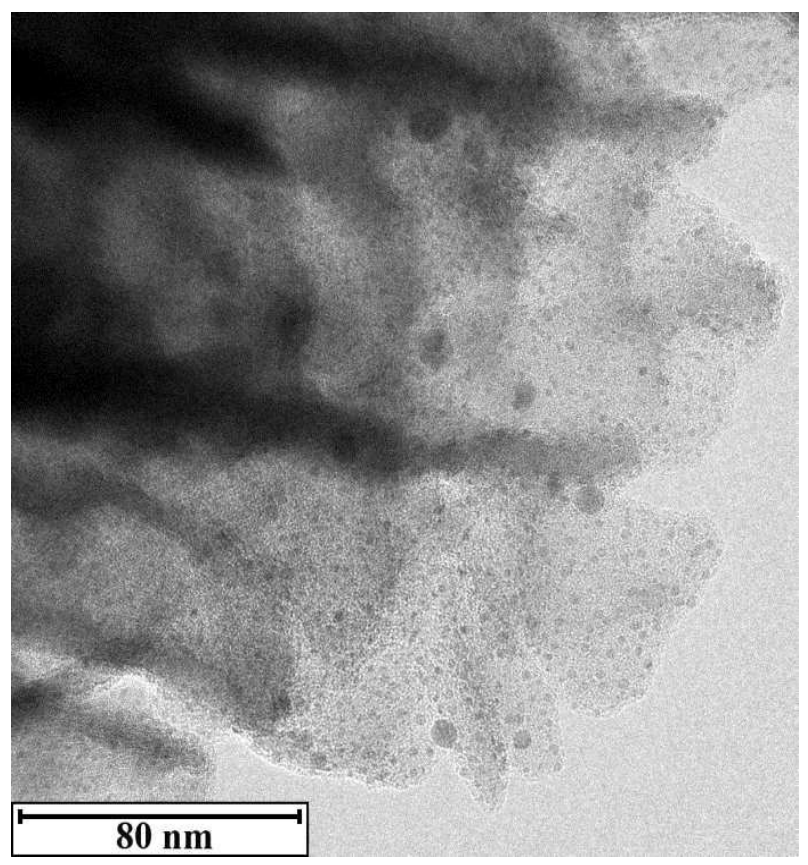

Fig. 4 a Nanotube mouth of NSAgOh

To verify this assumption the scratched nanotubes were transferred in isopropyl alcohol suspension onto thy lacy carbon grid. After the evaporation of alcohol, individual tubes were observed by TEM. The photochemical method by which the silver was created in the tubes led to the formation of a large number of nanoparticles (Fig. $4 a)$. They had different sizes and were present along the whole lengths, also at the bottom (Fig. 4b) of the tubes. Silver nanoparticles were very fine, their size was in the units of nanometres up to $15 \mathrm{~nm}$ (Fig. 4c). TEM-EDS analysis was performed on individual nanotubes, separated on a grid. There was detected $5.7 \pm 1.7$ wt. $\%$ of silver.

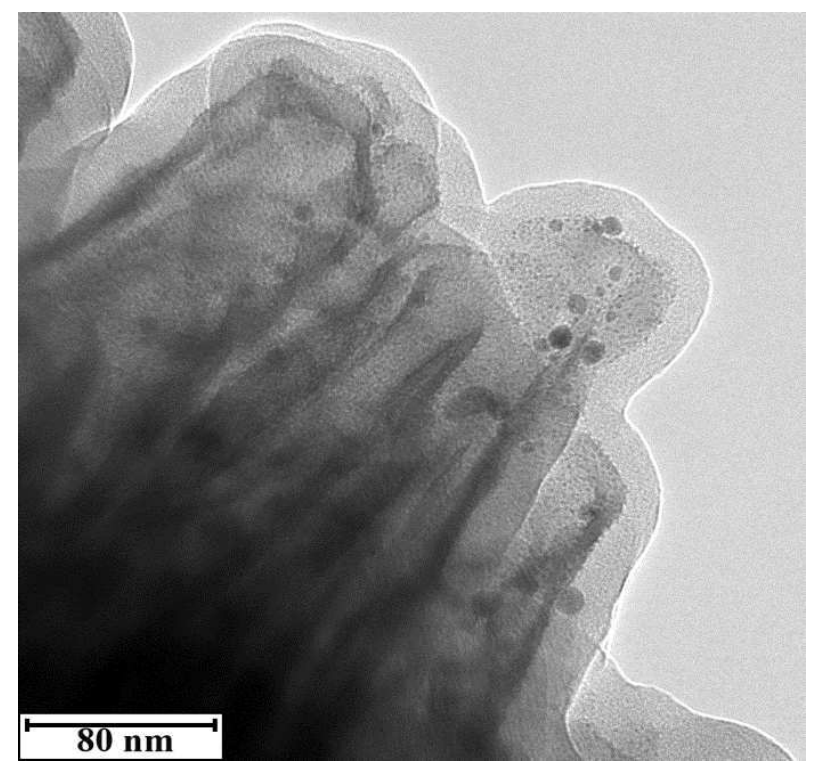

Fig. $4 \boldsymbol{b}$ Nanotube bottom of NSAgOh

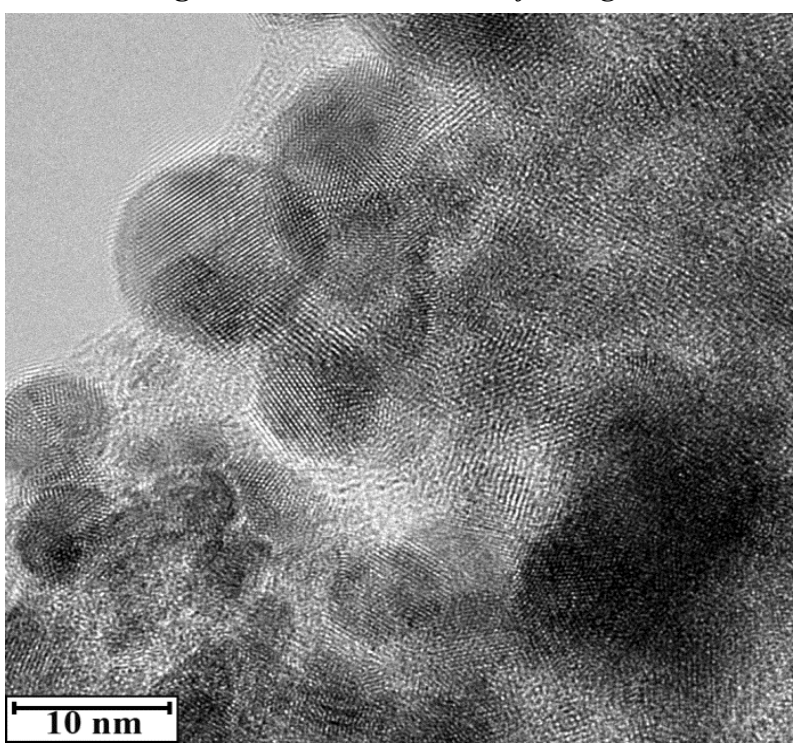

Fig. $4 \mathrm{c}$ Varied sizes of silver nanoparticles inside the nanotube

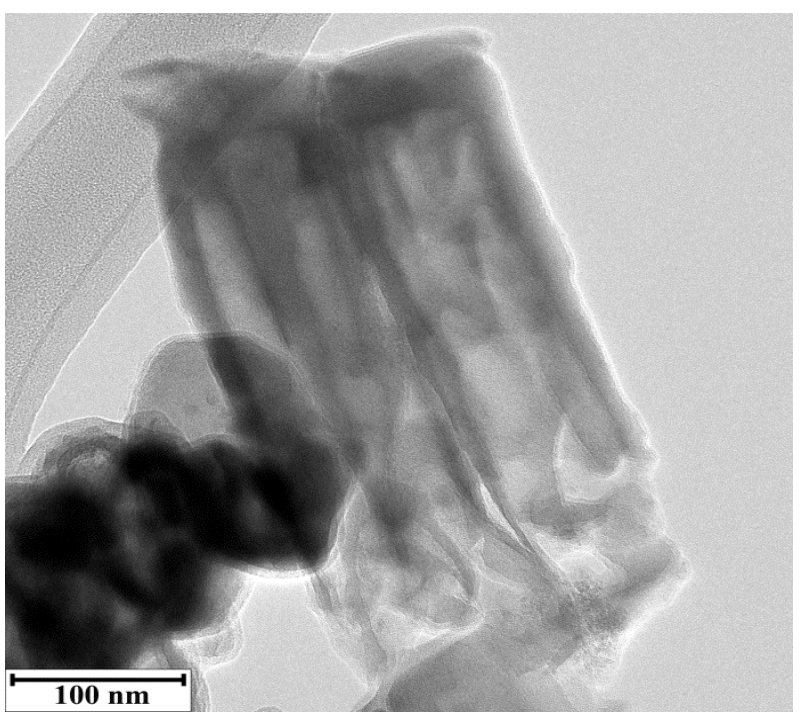

Fig. 5 Separated nanotubes after 48 hours of exposure in PS, without silver nanoparticles 
The data from SEM-EDS analysis (Tab. 1) before and after exposure in PS were acquired from discs samples. During the first 24 hours of exposition, only a part of silver was released. The part of silver nanoparticles was available on the surface and the other main portion was inside the nanotubes. Silver has not been released from the volume of nanotubes until 24 hours of exposure. Silver dissolution was covered by the surface sources during this period, which is confirmed by a small decrease in silver content. Nanoparticles were still present inside the nanotubes and available for antibacterial activity. Silver nanoparticles were released from nanotubes reservoirs mainly in the period from 24 to 48 hours. It was also confirmed by the TEM image obtained on samples NSAg48h. Nanotubes were empty without silver nanoparticles (Fig. $5)$.

Tab. 1 SEM-EDS results before and after exposure in PS

\begin{tabular}{|c|c|}
\hline sample & wt. \% Ag \\
\hline NSAg0h & $1.15 \pm 0.25$ \\
\hline NSAg12h & $1.15 \pm 0.12$ \\
\hline NSAg24h & $0.95 \pm 0.30$ \\
\hline NSAg48h & $0.08 \pm 0.09$ \\
\hline
\end{tabular}

For the antimicrobial activity testing, S. aureus was used because this species is present in most cases of bacterial contamination associated with medical devices. Samples filled with nanosilver indicated very good antibacterial activity at all (Fig. 6). Ground TiAlV sample was a positive control having no antibacterial activity. The pure silver sample was used as a negative control, maximal inhibition was expected. Unexposed samples with the highest silver content attained almost $100 \%$ antimicrobial efficiency. As it is obvious, NSAg0h exhibited higher antimicrobial activity than control sample. Silver sample has completed the preparation process consisted of grinding followed by the exposure to the air before antibacterial testing itself. Thus, its surface condition was different from that on $\mathrm{NSAg} 0 \mathrm{~h}$, which has moreover quite large area. There was an evident chemical effect on the control sample, which likely caused the precipitation of the blocking layer, resulting in different antibacterial effects compared to NSAg0h. The main reason was probably in the important difference of surface area. Thus, silver nanoparticles acted easily than the pure silver.

Behaviour of samples after 12 and 24 hours of exposure in PS was comparable with a negative control. In this first phase of the exposure, silver was released from the surface. The amount of silver nanoparticles in nanotubes was probably not influenced during this step.

Even after 48 hours, the samples exhibited inhibitory effects on the tested bacterial strain. The efficacy was approximately $50 \%$ lower than that of the samples with the highest tested silver content, but still achieved the inhibition of $55 \%$ of the pathogens. Between $24^{\text {th }}$ and $48^{\text {th }}$ hour of exposure, the mechanism of silver release from the volume of nanotubes was obvious as it is documented by the apparent decrease of silver concentration, see SEM-EDS data (Tab. 1).

To sum up briefly, antibacterial activity of exposed specimens declined. This is consistent with the decrease in silver concentration (Tab. 1). Antibacterial activity was confirmed in the case of all tested samples.

98

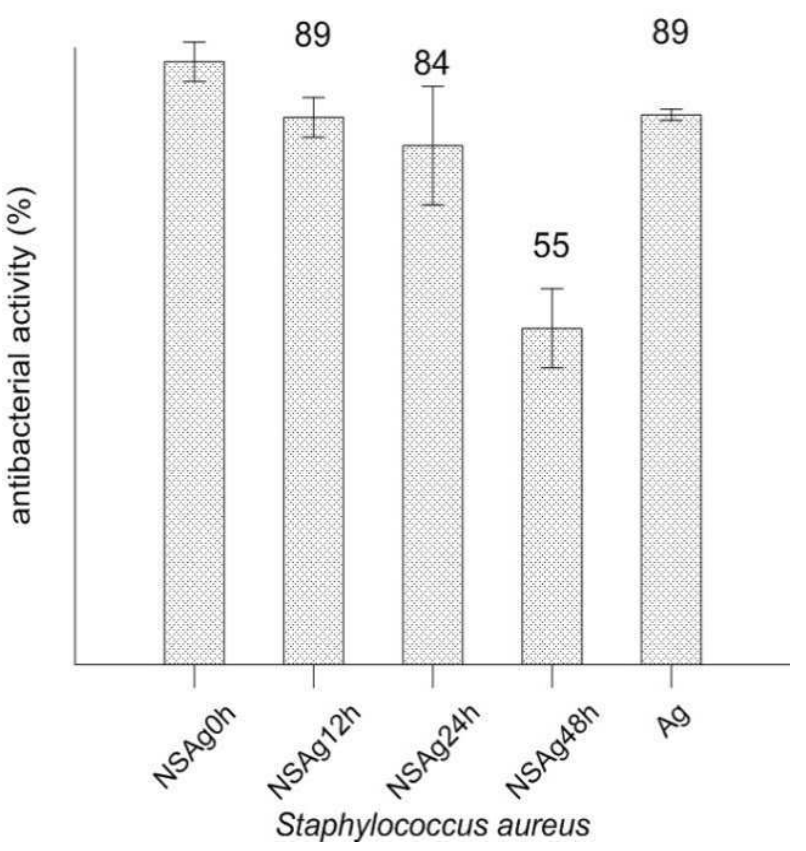

Fig. 6 Graph summarizing the results of antibacterial activity test against $S$. aureus bacteria

\section{Conclusion}

The nanostructured surface of the Ti6Al4V alloy was successfully prepared. The silver nanoparticles were deposited by the combination of the ultrasonication and photo-reduction. Chosen method allowed the transport of a solution containing silver ions into the entire volume of nanotubes. The subsequent photo-reduction led to the formation of silver nanoparticles within nanotubes. The presence of silver nanoparticles was confirmed by transmission electron microscopy. Modified surfaces showed a high antibacterial activity against $S$. aureus. Antibacterial efficiency decreased with exposure time; however, it was still at the $50 \%$ level after 48 hours. The combination of the nanostructure and silver nanoparticles seems to be a useful surface treatment for medical applications.

\section{Acknowledgement}

This work was carried out as a part of the project $\mathrm{Nr}$. 15-27726A (Czech Health Research Council) Technologies of nano-tubes and nano-silver for antibacterial surface treatment of orthopedic implants.

\section{References}

[1] DONACHIE, M. J. (2000). Titanium: A technical guide. Materials Park: ASM International, Vol. 2

[2] FOUSOVÁ, M., VOJTĚCH, D., KUBÁSEK, J. (2016). Titanium alloy Ti-6Al-4V prepared by Selective Laser Melting (SLM). In: Manufacturing Technology, Vol. 16, No. 4, pp. 691-697.

[3] MACAK, J. M., SCHMUKI, P. (2006). Anodic growth of self-organized anodic $\mathrm{TiO} 2$ nanotubes 
in viscous electrolytes. In: Electrochimica Acta, Vol. 52, No. 3, pp. 1258-1264.

[4] MACAK, J. M., ALBU, S., KIM, D. H., PARAMASIVAM, I., ALDABERGEROVA, S., SCHMUKI, P. (2007). Multilayer TiO2-nanotube formation by two-step anodization. In: Electrochemical and Solid State Letters, Vol. 10, No. 7, pp. K28-K31.

[5] FOJT, J. (2012). Ti-6Al-4V alloy surface modification for medical applications. In: Applied Surface Science, Vol. 262, No., pp. 163-167.

[6] FILOVA, E., FOJT, J., KRYSLOVA, M., MORAVEC, H., JOSKA, L., BACAKOVA, L. (2015). The diameter of nanotubes formed on Ti$6 \mathrm{Al}-4 \mathrm{~V}$ alloy controls the adhesion and differentiation of\&nbsp;Saos-2 cells. In: International Journal of Nanomedicine, No., pp. 7145.

[7] ERCAN, B., KUMMER, K. M., TARQUINIO, K. M., WEBSTER, T. J. (2011). Decreased Staphylococcus aureus biofilm growth on anodized nanotubular titanium and the effect of electrical stimulation. In: Acta Biomater, Vol. 7, No. 7, pp. 300312.

[8] FERRARIS, S., SPRIANO, S. (2016). Antibacterial titanium surfaces for medical implants. In: Mater Sci Eng C Mater Biol Appl, Vol. 61, No., pp. 965-78.

[9] MOHAMMED, M. T., KHAN, Z. A., SIDDIQUEE, A. N. (2014). Surface Modifications of Titanium Materials for developing Corrosion Behavior in Human Body Environment: A Review. In: Procedia Materials Science, Vol. 6, No., pp. 1610-1618.

[10] ARENAS, M. A., PEREZ-JORGE, C., CONDE, A., MATYKINA, E., HERNANDEZ-LOPEZ, J. M., PEREZ-TANOIRA, R., DE DAMBORENEA, J. J., GOMEZ-BARRENA, E., ESTEBA, J. (2013). Doped TiO2 anodic layers of enhanced antibacterial properties. In: Colloids Surf B Biointerfaces, Vol. 105, No., pp. 106-12.

[11] [11]GALLARDO-MORENO, A. M., MULTIGNER, M., PACHA-OLIVENZA, M. A., LIEBLICH, M., JIMENEZ, J. A., GONZALEZCARRASCO, J. L., GONZALEZ-MARTIN, M. L. (2009). Influence of slight microstructural gradients on the surface properties of Ti6Al4V irradiated by UV. In: Appl. Surf. Sci., Vol. 255, No. 22, pp. 9105-9111.
[12] SINGH, M., SINGH, S., PRASAD, S., GAMBHIR, I. (2008). Nanotechnology in medicine and antibacterial effect of silver nanoparticles. In: Digest Journal of Nanomaterials and Biostructures, Vol. 3, No. 3, pp. 115-122.

[13] SILVER, S. (2003). Bacterial silver resistance: molecular biology and uses and misuses of silver compounds. In: FEMS Microbiology Reviews, Vol. 27, No. 2-3, pp. 341-353.

[14] BOSETTI, M., MASSE, A., TOBIN, E., CANNAS, M. (2002). Silver coated materials for external fixation devices: in vitro biocompatibility and genotoxicity. In: Biomaterials, Vol. 23, No. 3, pp. 887-892.

[15] HARRASSER, N., JÜSSEN, S., BANKE, I. J., KMETH, R., VON EISENHART-ROTHE, R., STRITZKER, B., GOLLWITZER, H., BURGKART, R. (2015). Antibacterial efficacy of titanium-containing alloy with silver-nanoparticles enriched diamond-like carbon coatings. In: AMB Express, Vol. 5, No., pp. 77.

[16] ZHANG, W., LIU, W., LIU, Y., WANG, C. (2009). Tribological behaviors of single and dual sol-gel ceramic films on Ti-6Al-4V. In: Ceramics International, Vol. 35, No. 4, pp. 1513-1520.

[17] CHANG, C., HUANG, X., LIU, Y., BAI, L., YANG, X., HANG, R., TANG, B., CHU, P. K. (2015). High-current anodization: A novel strategy to functionalize titanium-based biomaterials. In: Electrochimica Acta, Vol. 173, No., pp. 345353.

[18] ZLAMAL, M., MACAK, J. M., SCHMUKI, P., KRÝSA, J. (2007). Electrochemically assisted photocatalysis on self-organized $\mathrm{TiO} 2$ nanotubes. In: Electrochemistry Communications, Vol. 9, No. 12 , pp. 2822-2826.

[19] HOU, X., MAO, D., MA, H., AI, Y., ZHAO, X., DENG, J., LI, D., LIAO, B. (2015). Antibacterial ability of Ag-TiO2 nanotubes prepared by ion implantation and anodic oxidation. In: Materials Letters, Vol. 161, No., pp. 309-312.

[20] ESFANDIARI, N., SIMCHI, A., BAGHERI, R. (2014). Size tuning of Ag-decorated TiO2 nanotube arrays for improved bactericidal capacity of orthopedic implants. In: Journal of Biomedical Materials Research Part A, Vol. 102, No. 8, pp. 2625-2635. 